\title{
Electrokinetic flushing with surrounding electrode arrangements for the remediation of soils that are polluted with 2,4-D: A case study in a pilot plant
}

\author{
C. Risco ${ }^{\text {a }}$, S. Rodrigo ${ }^{\text {a }}$, R. López-Vizcaíno ${ }^{\text {a }}$, C. Sáez ${ }^{\text {b }}$, P. Cañizares ${ }^{\text {b }}$, V. Navarro ${ }^{\text {c }}$, M.A. Rodrigo ${ }^{\text {b, } *}$ \\ a Department of Chemical Engineering, Instituto de Tecnologías Química y Medioambiental, University of Castilla-La Mancha, Campus Universitario s/n, 13071 Ciudad Real, Spain \\ b Department of Chemical Engineering, Facultad de Ciencias y Tecnologías Químicas, University of Castilla-La Mancha, Campus Universitario s/n, 13071 Ciudad Real, Spain \\ c Geoenvironmental Group, Civil Engineering School, University of Castilla-La Mancha, Avda. Camilo José Cela s/n, 13071 Ciudad Real, Spain
}

\section{H I G H L I G H T S}

- EKSF can be efficiently applied for the removal of ionic herbicides from soils.

- EKSF with a 1c6a configuration is very efficient for the removal of 2,4-D from soils.

-2,4-D is mobilized favorably by electromigration to the anodic wells.

- Configuration 1c6a transfers $70 \%$ of the 2,4-D to flushing water in only 35 days.

- Configuration 1a6c transfers less than $8 \%$ of the $2,4-\mathrm{D}$ to flushing fluid in 58 days.
G R A P H I C A L A B S T R A C T

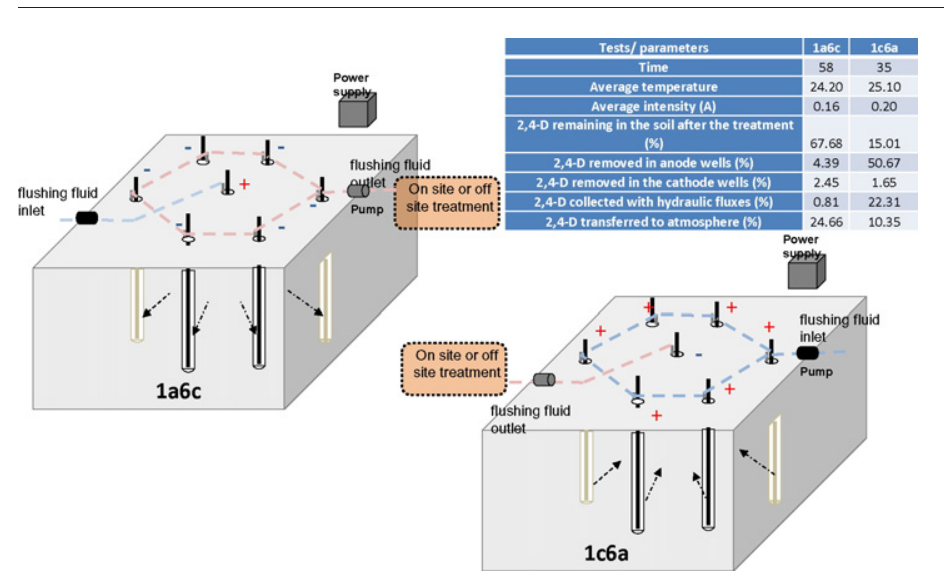

\begin{abstract}
A B S T R A C T
This work aimed to evaluate electrokinetic soil flushing (EKSF) technologies for the removal of 2,4dichlorophenoxyacetic acid (2,4-D) from spiked soils using an electrode configuration consisting of one cathode surrounded by six anodes ( $1 \mathrm{c} 6 \mathrm{a}$ ) and one anode surrounded by 6 cathodes (1a6c). Experiments were conducted for over one month in a bench-scale set-up $\left(175 \mathrm{dm}^{3}\right.$ of capacity) that was completely automated and operated at a constant electric field $\left(1.0 \mathrm{~V} \mathrm{~cm}^{-1}\right)$. The electrical current, temperature, $\mathrm{pH}$, moisture and pollutant concentration in electrolyte wells were monitored daily, and at the end of the experiments, an in-depth sectioned analysis of the complete soil section (post-mortem analysis) was conducted. Despite the geometric similarity, the two strategies led to very different results mainly in terms of water and herbicide mobilization, whereas $\mathrm{pH}$ and conductivity do not depend strongly on the electrode configuration. The volume of water extracted from cathodes with 1a6c is seven times higher than that of the 1c6a strategy. Herbicide was transported to the anode wells by electromigration and then dragged toward the cathode wells by electro-osmotic fluxes, with the first process being much more important. The configuration 1c6a was the most efficient and attained a transfer of $70 \%$ of the herbicide contained in the soil to flushing water in 35 days. These results outperform those obtained by the
\end{abstract}

\footnotetext{
* Corresponding author.

E-mail address: manuel.rodrigo@uclm.es (M.A. Rodrigo).
} 
configuration $1 \mathrm{a} 6 \mathrm{c}$, for which less than $8 \%$ of the herbicide was transferred to flushing fluids in a much longer time (58 days).

\section{Introduction}

Soil pollution is an environmental problem of major significance (Virkutyte et al., 2002). There are many types of pollutants and numerous types of technologies for the remediation of each pollutant. Among these types, electroremediation technologies have received increasing interest in recent years (Rodrigo et al., 2014; Ribeiro et al., 2005; Ribeiro et al., 2011). When direct current (DC) is applied to a group of electrodes that are located in the polluted soil, several processes become activated, such as electrochemical reactions (mainly water oxidation and reduction on the surfaces of the electrodes), heat transfer (associated with ohmic drops) and electrokinetic transport processes (electromigration, electrophoresis and electro-osmosis). These processes favor the transport of pollutants and their removal from the soil (Virkutyte et al., 2002; Page and Page, 2002; Saichek and Reddy, 2005; Pazos et al., 2010).

One of the key points of this novel technology is the arrangement of electrodes in the soil because this arrangement may help contain the pollution (fence technologies) or transport it to the collecting points (flushing fluid technologies). Thus, the electrode configuration selected in the treatment is a key operational factor as it could determine the direction and magnitude of the electrokinetic processes and, consequently, the efficiency in the transport of pollutants for each particular case. This topic has gained importance in recent years, with many studies focusing on the evaluation of the electrode configuration (Alshawabkeh et al., 1999; Turer and Genc, 2005; Almeira et al., 2009; Cho et al., 2012; Kim et al., 2012a; Kim et al., 2012b; Peng et al., 2013; Kim et al., 2014; Jeon et al., 2015). A common conclusion is that the most effective electrode configurations from the viewpoint of the transport of pollutants are rings of anodes with a central cathode or vice versa (depending on the chemical structure and physico-chemical properties of the pollutant). Most previously published studies have focused on the remediation of soils that are contaminated with metal ions because this is the most important application of electroremediation and is currently considered a cost-efficient and mature technology.

However, in recent years, an increasing interest in the electroremediation of soils with organic pollutants has appeared. In particular, the removal of pesticides has become a popular topic (Jackman et al., 2001). The application of these type of compounds is very common in most agricultural regions of the world, but their excessive use can jeopardize the quality of soil and water and have serious effects on drinking water reservoirs (Sheng et al., 2001). The herbicide 2,4-dichlorophenoxy acetic acid (2,4-D) is one of the most frequently used pesticides (Munro et al., 1992); from a chemical point of view, its high solubility and acidic properties should be considered in the design of a remediation strategy. Many papers have focused on the removal of this herbicide from surface water or groundwater (Fang et al., 2012; Bian et al., 2013; de Velosa and Pupo Nogueira, 2013; Girardi et al., 2013; Niedree et al., 2013; Garcia et al., 2014; Ordaz-Guillen et al., 2014; Zhou et al., 2014; Maya-Trevino et al., 2015; Schenone et al., 2015; Fontmorin et al., 2013; Garcia et al., 2013), but very few have focused on its removal from soil.

In this context, electrokinetic remediation could be a good alternative to contain and/or remove organic pollutants from soil. Electrokinetic soil flushing (EKSF) is becoming one of the most promising technologies for soil remediation, especially when the pollutant consists of ionic species. An electric field between anodes and cathodes that are placed in the soil is the driving force of electrokinetic processes. The electro-osmosis induced by the application of an electric field drains pollutants to the cathode wells, where they can be easily collected. In the case of ionic pollutants, electromigration is also expected to strongly influence their concentration because the electric field promotes the transport of the ionic pollutants to electrode wells of opposite charge. In the case of anionic pollutants, such as the 2,4-D herbicide, these electrodes are the anodes. Consequently, a very complex pattern of flows is produced in soils that undergo an EKSF process. Because of the contribution of these processes, in light of the present knowledge of the technology, it is difficult to predict the performance of this type of treatment; as a result, studies investigating the scale-up of such technology are required, particularly to shed light on the combined effect of the processes that occur when an electric field is applied. As previously noted, one of the most important inputs to be evaluated is the electrode arrangement; thus, in this study, two different electrode array configurations are studied (Fig. 1) in a bench-scale plant with 1751 of spiked soil polluted with 2,4-D: a central cathode that is surrounded by six anodes (1c6a) and a central anode that is surrounded by six cathodes (1a6c). Despite having the same number of electrodes, the expected results are completely different because the main flows occur in different directions. This manuscript reports the main results obtained during the two tests and compares them with the results obtained in a reference test, in which the dispersion of the pollutant in a soil that did not undergo an electric field is evaluated.

\section{Materials and methods}

\subsection{Materials}

The soil used in this study was from a quarry located in Toledo (Spain) (Lopez-Vizcaino et al., 2014a; Lopez-Vizcaino et al., 2014b). This soil is characterized by its inertness, low hydraulic conductivity and lack of organic content. Table 1 shows the qualitative mineralogical composition obtained by X-Ray diffraction analysis, parameters used to classify this soil by the Unified Soil Classification System (USCS) and granulometry of soil estimated by Laser Diffraction Particle Size Analyzer. The 2,4-dichlorophenoxyacetic acid (2,4-D) that was used as the herbicide model was of analytical grade (Sigma-Aldrich). It is a weak acidic molecule ( $\mathrm{pKa}=2.6$ ) with an octanol/water partition coefficient of 2.83 $\left(\log \mathrm{K}_{\mathrm{ow}}\right)$ and vapor pressure of $1.9 \cdot 10^{-5} \mathrm{~Pa}\left(\right.$ at $\left.25^{\circ} \mathrm{C}\right)$.

\subsection{Preparation of the polluted soil}

The soil preparation process is important because of the complexity of natural soil. The process was divided into different stages as follows: 1) positioning three layers of gravel with different granularities for mechanical and drain support; 2) moistening and compacting the soil in the electrokinetic reactor by compacting layers of a fixed height $(5 \mathrm{~cm})$ to attain the typical moisture and dry density of a real soil (initial moisture of $20 \%$ and dry density of $1.4 \mathrm{~g} \mathrm{~cm}^{-3}$, as determined from the standard Proctor compaction tests and the Standard ASTM D698, respectively); and 3) drilling the electrolyte wells and implementing the instrumentation of the plant. At the top of the soil, a capillary barrier consisting of a ca. 2-cm-wide layer of sand was placed to minimize the evaporation of water and the volatilization of the herbicide. In the reference test that assessed the dispersion of the pollutant, the width of the barrier was $1 \mathrm{~cm}$.

\subsection{Experimental setup}

The electrokinetic experiments were conducted in an electrokinetic remediation plant consisting of an electrokinetic reactor, power source and tanks of electrolyte. The reactor was a methacrylate prism with a 

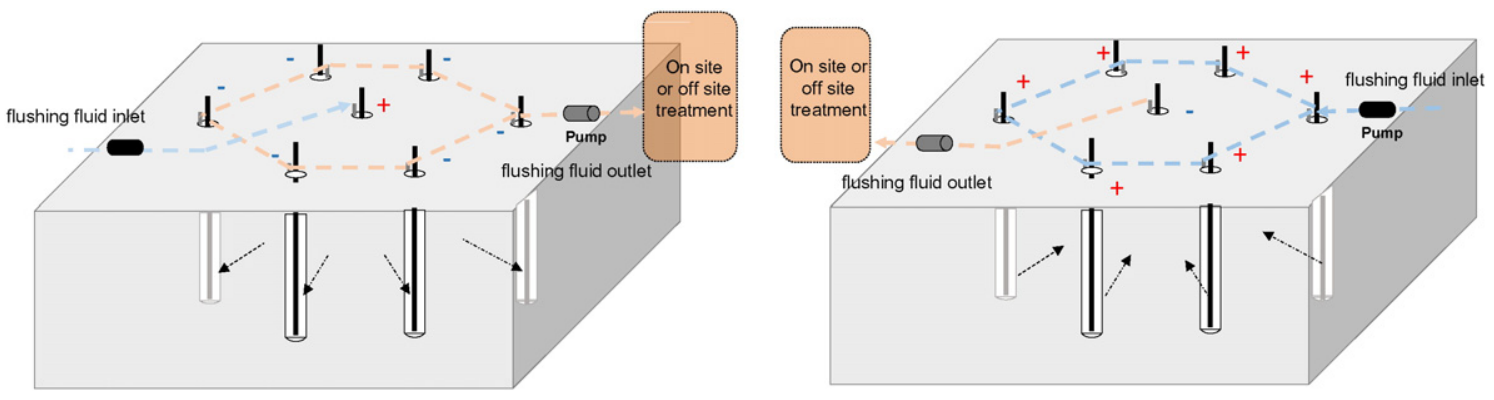

Fig. 1. EKSF with rows of cathodes surrounding an anode and rows of anodes surrounding a cathode.

soil capacity of $175 \times 10^{3} \mathrm{~cm}^{3}\left(\mathrm{LWH}: 70 \times 50 \times 50 \mathrm{~cm}^{3}\right)$. The electrodes that were used for both the anodes and the cathodes were graphite rods with dimensions of $1 \times 1 \times 10 \mathrm{~cm}^{3}$. These rods were positioned in semipermeable electrolyte wells with two different electrode array configurations: a central cathode that was surrounded by six anodes (1c6a) and a central anode that was surrounded by six cathodes (1a6c). The configuration is designed to separate and collect fluids through an outlet situated on the side wall of the reactor. To monitor the flux of water and the temperature evolution during the experiment, tensiometers, thermocouples and rhizons were inserted into the soil. Fig. 2 presents a diagram of the electrokinetic remediation plant (part a) and the instrumentation of the plant (part b) with the notations that will be used in the discussion of the results.

\subsection{Experimental procedure}

Once the plant was completely instrumented, the experimental procedure began by polluting the soil (simulating accidental spill). Thus, in the central point of the electrokinetic reactor, an accidental leak of

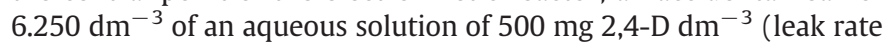
of $0.085 \mathrm{dm}^{3} \mathrm{~h}^{-1}$ ) was simulated. Next, the electrolyte wells (water, $\mathrm{pH} 7.64$ and $0.391 \mathrm{mS} \mathrm{cm}^{-1}$ conductivity) were filled. The level of each electrolyte well was controlled by a level control system. In the case of anodic wells, it was connected to the feed-anolyte tank that adjusted the volume of water added to the soil, and in the case of cathodic wells, it was connected to the reservoir-cathodic tank that adjusted the volume of water extracted from the cathodic wells. The test began when the power source, a 400 SM-8-AR ELEKTRONIKA DELTA BV, turned on and applied a constant voltage gradient of 1 Volt Direct Current (VDC) $\mathrm{cm}^{-1}$.

Table 1

Qualitative mineralogical composition of the soils, classification by the USCS and granulometry.

\begin{tabular}{ll}
\hline Mineral & \\
\hline Quartz & \\
Feldspar & \\
Calcite & \\
Kaolinite & \\
Smectite & \\
Illite & \\
Organic content $=0 \%$ & 42 \\
& \\
Parameters USCS & 24 \\
\hline Liquid limit & 18 \\
Plastic limit & CL \\
Plasticity index & \\
USCS Code & \\
Granulometry & 4.9 \\
\hline$\%<2 \mu \mathrm{m}$ & 68.2 \\
$2 \mu \mathrm{m}<\%<60 \mu \mathrm{m}$ & 26.9 \\
$\%>60 \mu \mathrm{m}$ &
\end{tabular}

The electrical current, temperature, $\mathrm{pH}$, moisture and 2,4-D concentration in the electrolyte wells were monitored daily, and at the end of the experiments, an in-depth sectioned analysis of the complete soil section was performed. To perform this analysis, the soil was divided into 16 superficial zones $(4 \times 4)$ and 3 different 1 -cm thick layers (surface, middle and bottom layers). Hence, the anolyte sampling was conducted manually, whereas the catholyte sampling was conducted by pumping the water accumulated in the cathodic wells. The gravity fluid was sampled daily $\left(5 \mathrm{~cm}^{3}\right)$ and then drained at the end of the process through an outlet that was situated at the bottom of the reactor. In the reference test, the electric field was not applied to guarantee the natural dispersion of the pollution. The soil was not handled until days 26 and 70, when soil samples were obtained to determine the pH, conductivity, moisture and 2,4-D concentration distribution in the soil matrix.

\subsection{Analyses}

To quantify the amount of 2,4-D in the soil, an L-S extraction process was used. This process was performed in Eppendorf tubes $(15 \mathrm{ml})$ using water as a solvent (ratio polluted soil/solvent $=0.2 \mathrm{w} / \mathrm{w}$ ). Both phases were vigorously stirred in a vortex mixer multi-tube, VV3 VWR, and the subsequent phase separation was accelerated using a centrifuge rotor angular CENCOM II P-elite during 15 min, applying 3000 RPM. The 2,4-D concentration in the aqueous phase was determined using UVvisible spectrometry (Shimadzu UV-1603) at a wavelength of $283 \mathrm{~nm}$. The moisture and dry density of the soil were analyzed according to the ASTM Standards D2216 and ASTM D854, respectively. Measurements of $\mathrm{pH}$ and conductivity were carried out with an InoLab WTW pH-meter and a GLP 31 Crison conductimeter, respectively. The electric current was measured with a KEITHLEY 2000 Digital Multimeter. The temperature measurements were carried out with PT-100 thermocouples.

\section{Results and discussion}

Fig. 3 shows the changes in the current intensity during the two EKSF tests conducted in this work. In both tests, the applied electric field was $1.0 \mathrm{VDC} \mathrm{cm}^{-1}$. The duration initially scheduled for the experiments was approximately 1 month. However, once in operation and taking into account the less-efficient removal observed in the plant with the configuration 1a6c (six cathodes surrounding an anode), it was decided to extend this experiment for a longer time, explaining why its duration was slightly higher ( 35 days in the case of 1 c6a versus 58 days in the case of the 1 a6c configurations).

The resulting intensities of the two tests were comparable, despite the very different electrode arrangement used, and they settled from an initial value within the range of $0.3-0.4$ A down to values in the range $0.1-0.2 \mathrm{~A}$, with average values of 0.16 and $0.20 \mathrm{~A}$ in the $1 \mathrm{a} 6 \mathrm{c}$ and 1c6a strategies, respectively. Fluctuations in the resulting current intensity clearly indicate the coexistence of various processes, and the decreasing trend must be explained in terms of changes in the soil 


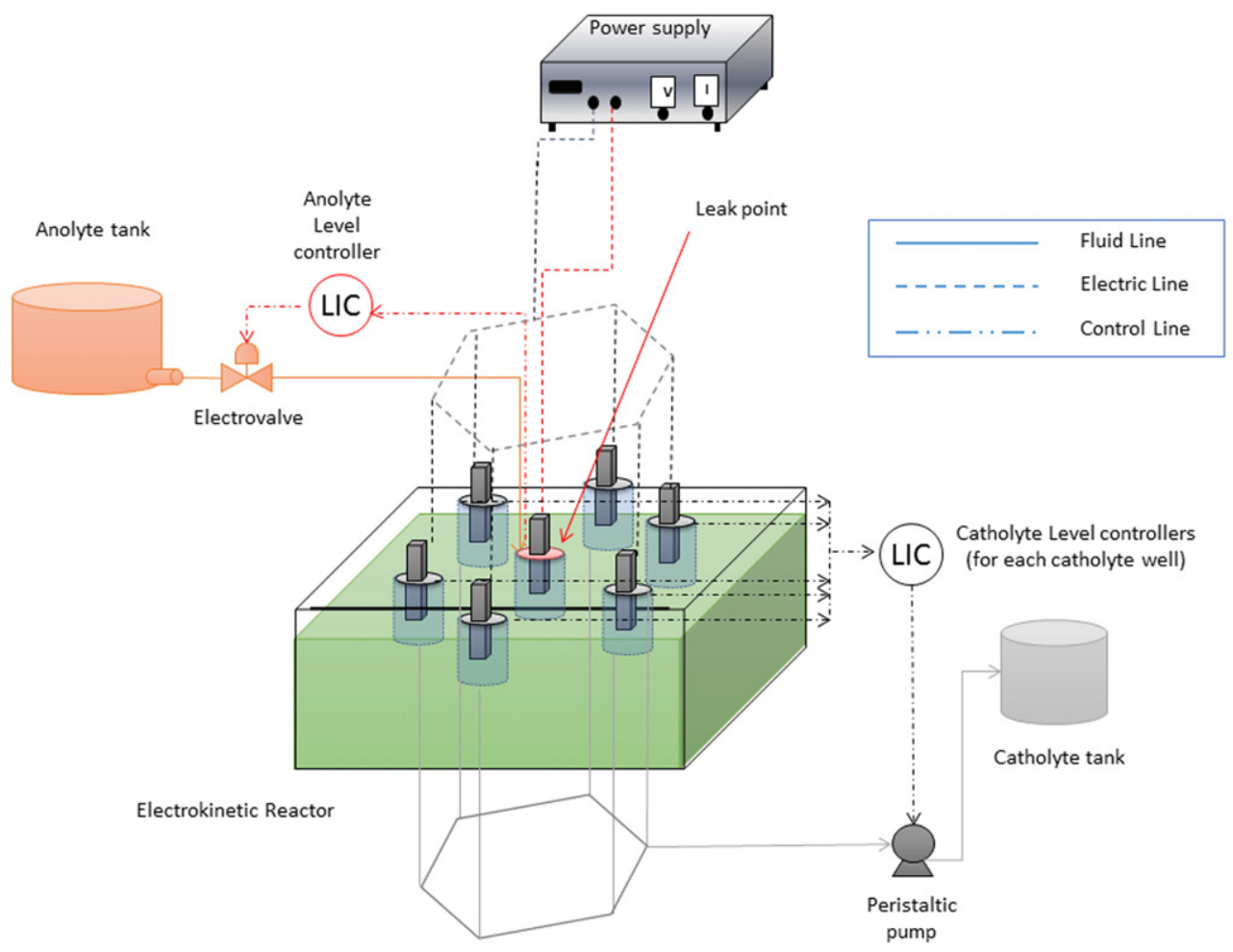

a)

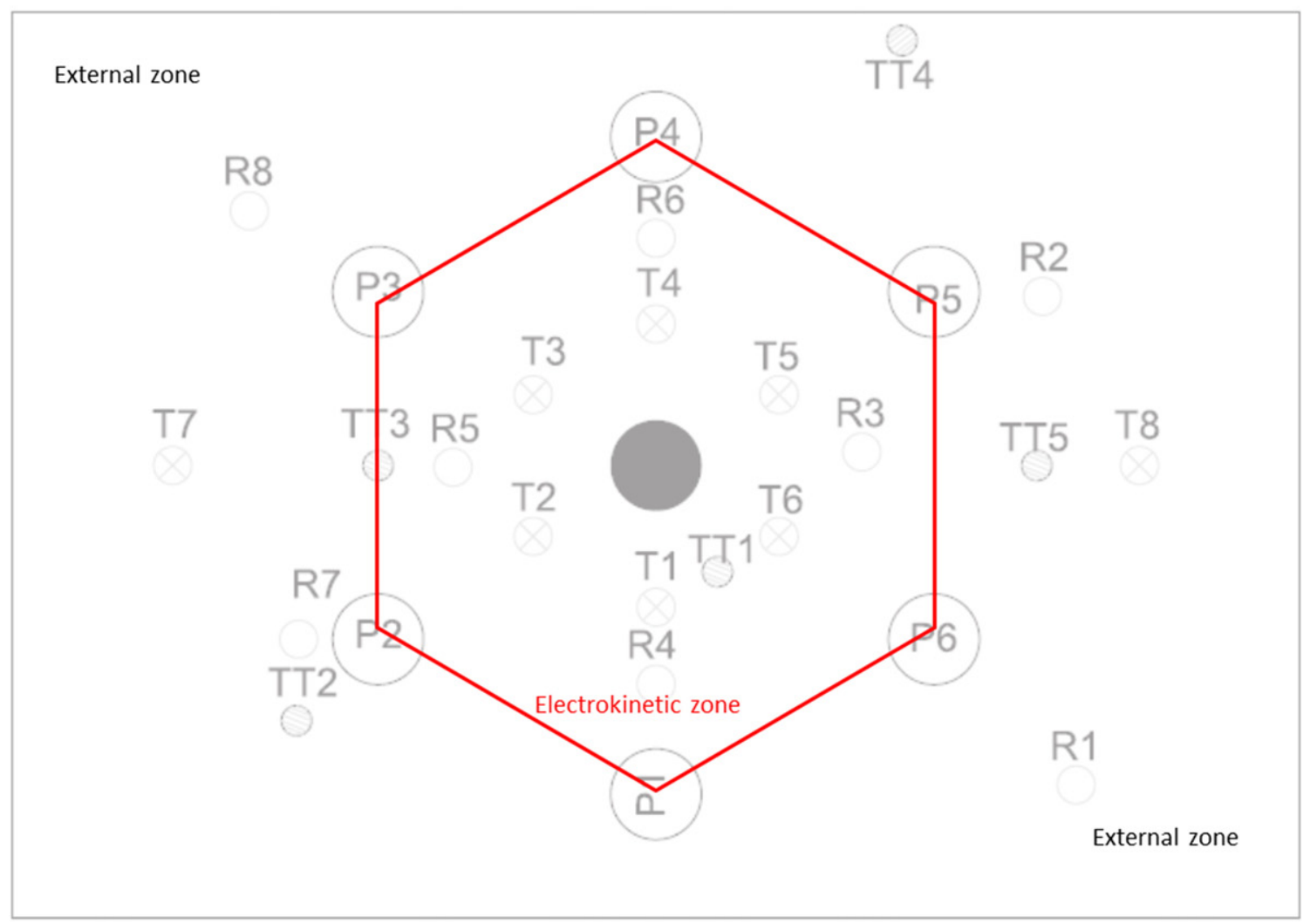

b)

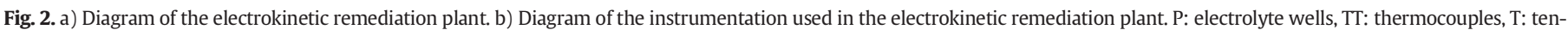
siometers, and R: rhizons. 

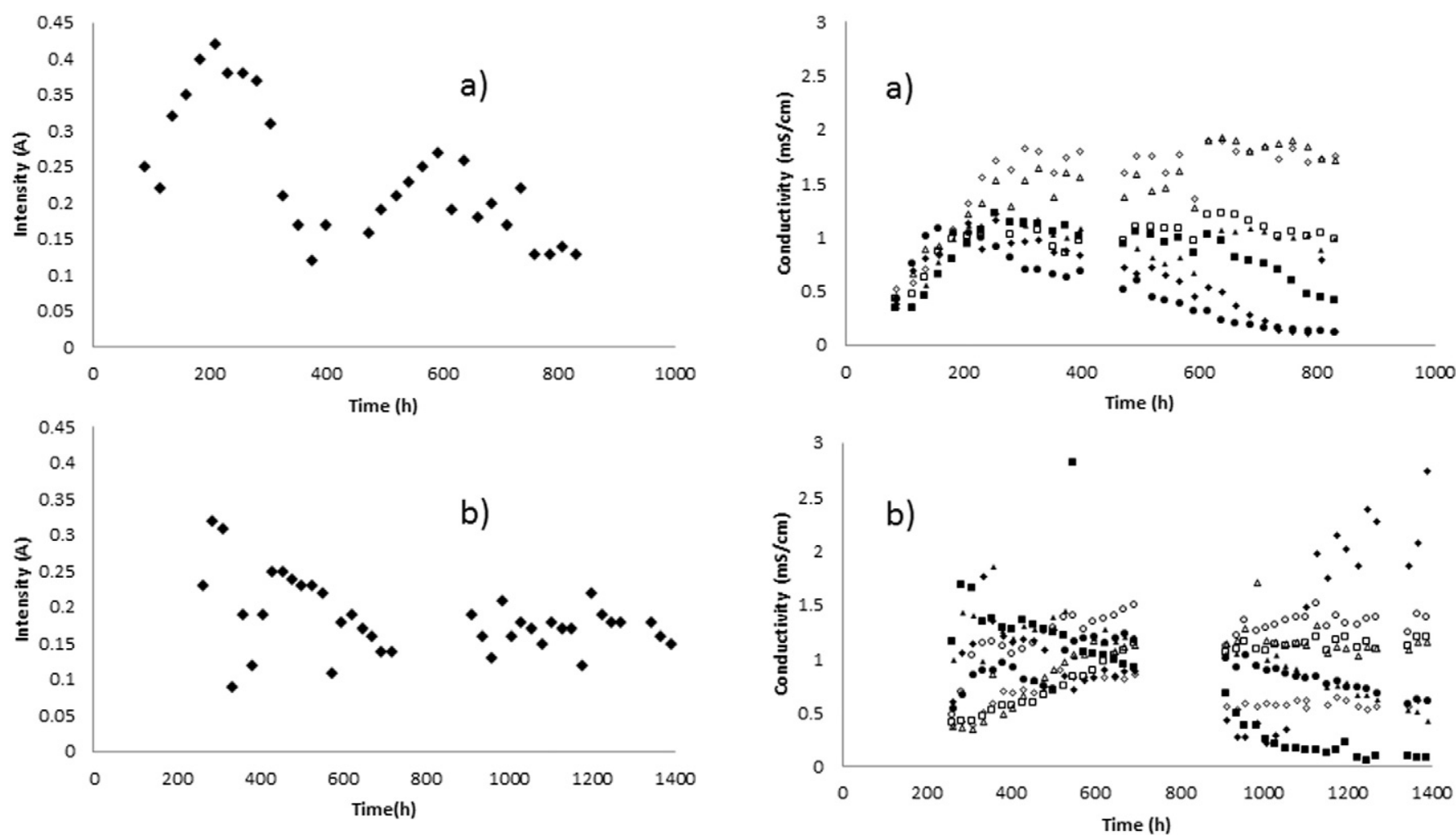

Fig. 3. Time course of the current intensity during the remediation test: a) 1c6a arrangement and b) $1 \mathrm{a} 6 \mathrm{c}$ arrangement.


b) 1a6c arrangement. External zone, unfilled marker: $(\diamond)$ R1, $(\square)$ R2, $(\Delta)$ R7, and $(O)$ R8. Electrokinetic zone, filled marker: $(\boldsymbol{\Delta})$ R3, ( $)$ R4, ( $\mathbf{\square})$ R5, and ( $)$ R6 (see Fig. 2).
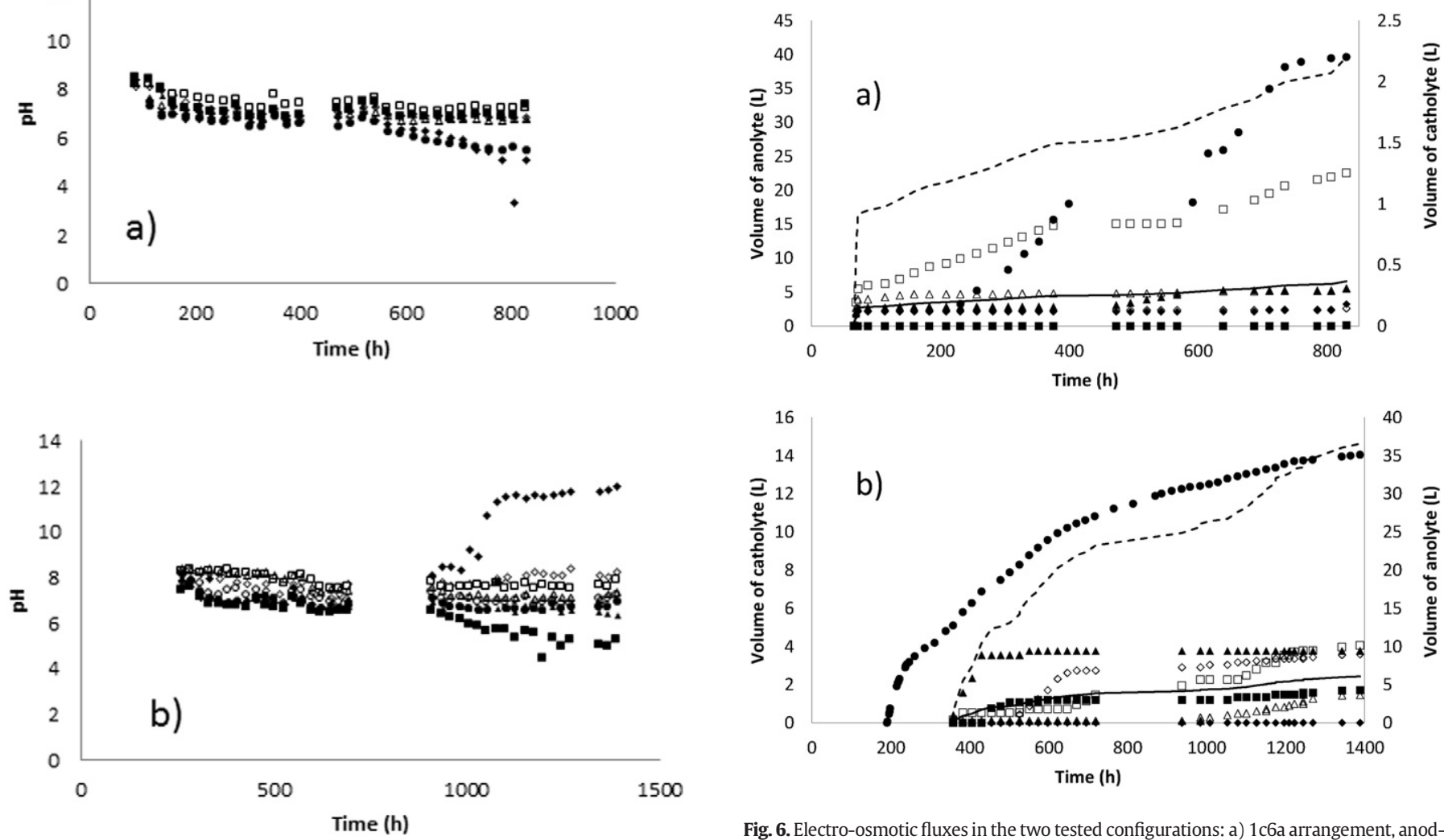

Fig. 6. Electro-osmotic fluxes in the two tested configurations: a) 1c6a arrangement, anod-

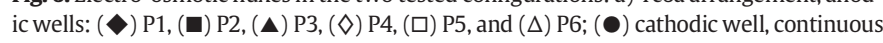
line: average accumulated volume in anodic wells; discontinuous line: total accumulated

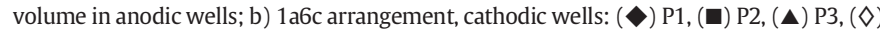
P4, ( $\square)$ P5, and $(\Delta)$ P6; $(\bullet)$ anodic well, continuous line: average accumulated volume in cathodic wells; discontinuous line: total accumulated volume in cathodic wells.

Fig. 4. Changes in the $\mathrm{pH}$ of the electrolyte wells during the two EKSF tests: a) 1c6a rangement and b) 1a6c arrangement. External zone, unfilled marker: $(\diamond)$ R1, ( $\square)$ R2 $(\Delta)$ R7, and $(O)$ R8. Electrokinetic zone, filled marker: $(\boldsymbol{\Delta}) \mathrm{R} 3,(\bullet) \mathrm{R} 4,(\boldsymbol{\square}) \mathrm{R} 5$, and $(\bullet)$ R6 (see Fig. 2). 
that led to an increase in the ohmic loses (Lopez-Vizcaino et al., 2014a; Lopez-Vizcaino et al., 2014b). This result is important because the soil must be considered a dynamic system with properties that undergo significant variations during remediation.

\subsection{Ionic transport}

One of the most important parameters in soil remediation is the $\mathrm{pH}$. Fig. 4 shows the changes in $\mathrm{pH}$ during the tests in eight sampling points placed inside and outside the zones that were surrounded by electrodes of the same polarity (so-called electrochemical and external zones, respectively). Due to the anodic oxidation and cathodic reduction of water, protons are formed on the anode and hydroxyl ions on the cathode surfaces according to the well-known electrochemical oxidation and reduction of water (Eqs. (1) and (2), respectively).

$$
\begin{aligned}
& \mathrm{H}_{2} \mathrm{O}-2 \mathrm{e}^{-} \rightarrow 1 / 2 \mathrm{O}_{2}+2 \mathrm{H}^{+} \\
& \mathrm{H}_{2} \mathrm{O}+\mathrm{e}^{-} \rightarrow 1 / 2 \mathrm{H}_{2}+\mathrm{OH}^{-}
\end{aligned}
$$

The transport of both ions to electrodes of opposite charge produces the well-known acidic and basic fronts, which can be clearly observed in the EKSF test, with rows of anode and cathode arrays facing each other (Lopez-Vizcaino et al., 2011; Mena et al., 2012). This process is known to negatively influence the properties of the soil, particularly if preventative actions are not taken, such as the neutralization of the electrolyte contained in the anode and/or cathode wells. In addition, this process is known to affect the ionic exchange, the precipitation/re-dissolution of species and the biological activity. When comparing the results obtained, note that in the external zone, only a slight decrease in the $\mathrm{pH}$ was observed during the tests and that no significant differences were obtained between the two configurations of electrodes. The same trend was also observed in the electrochemical zone, although in this case, the differences were more remarkable and the values that were monitored at various sampling points were substantially modified during the tests, due to both more acidic and alkaline values. The value obtained in well R4 in the test $1 \mathrm{a} 6 \mathrm{c}$ is particularly interesting because it is extremely alkaline. To explain these results, it is important to remember that the expected values are not close to the initial values of the electrolyte contained in the wells; rather, they are expected to be more extreme because of the production of the acidic and basic fronts. Hence, in most of the wells, the small changes must be explained in terms of effective neutralization of both fronts. In contrast, the extreme value of $\mathrm{pH}$ at other monitoring points clearly delimitated the places for which the $\mathrm{pH}$ is not adequately neutralized by the interaction of both $\mathrm{pH}$ fronts.

Changes in the conductivity were different in the inner (electrokinetic) and outer (external) zones of the soil in treatment (Fig. 5). In the outer zone, conductivity increased to a plateau, where it was maintained until the end of the tests. There was a small daily fluctuation, and important differences in the values obtained in the different rhizons were observed. Considering the symmetry of the setup, these differences must be explained in terms of the heterogeneity of the soil. In contrast, in the inner zone, the behavior was different. During the first stage ( shorter than in the case of the outer zone observation), there was an increase in the conductivity, but then the conductivity began to decrease in the samples that were taken in all rhizons, except for the samples
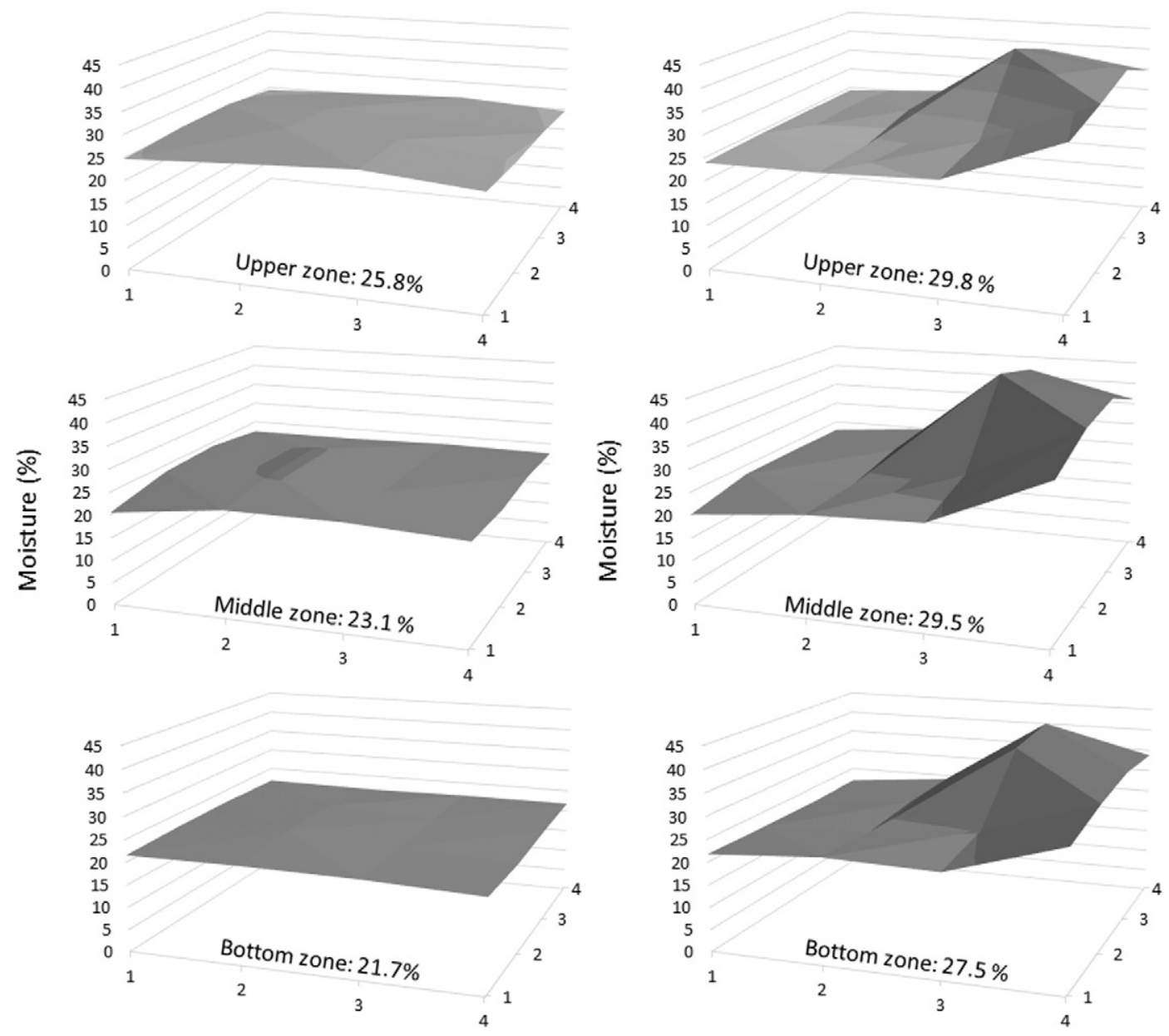

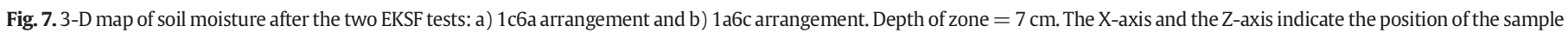
section. 
obtained in R4. This anomalous change can be explained in terms of the non-neutralization of the $\mathrm{pH}$ in the flushing fluid in this point, as previously noted. A different trend (from that of the $\mathrm{pH}$ changes) indicates that conductivity not only considers the concentration of hydroxyl and proton ions but also considers other ions. The decrease in the concentration after the initial stage in the zone inside the circular row of electrodes suggests some sort of ion depletion mechanism in this zone. This phenomenon does not occur in the external zone, as clearly indicated by the plateau in the conductivity in the external zone.

\subsection{Water transport}

The transport of water in soil is a very important characteristic for understanding EKSF processes. Because of the application of an electric field, the transport of water from the anode to the cathode wells by the well-known electro-osmosis is expected. Gravity and evaporation fluxes (perpendicular to the direction of the electro-osmotic transport) must also be considered in the water balance. All of these water fluxes can drain the pollutant and help remediate the soil in a full-scale application. Fig. 6 shows the totalized volumes of water added (anode wells) or extracted (cathode well) during the two tests.

In comparing the two tests, very important differences are apparent. When a six-cathode configuration (1a6c) is used, the volume of water extracted from cathodes is seven times higher than that of the 1c6a strategy, despite the volume added to the anode/s well/s being comparable. This observation means that vertical fluxes have a greater significance. Another important observation is the time lag between the addition of water in the anodic wells and the extraction from the cathodic wells, which is greater than $100 \mathrm{~h}$ in both cases. A final interesting point regarding the information supplied in this figure involves the differences that were observed in the water supplied to (multiple anodes in the 1c6a arrangement) or collected from (multiple cathodes in the $1 \mathrm{a} 6 \mathrm{c}$ arrangement) the electrode wells, despite the symmetry of the electrode arrangements. These differences indicate that the heterogeneity of the soils is a very important parameter and that, even for small setups with very-well controlled operation parameters, such as the systems studied in this work, it is difficult to obtain an accurate symmetry in performance. This observation is important to consider in the design of full-scale arrangements.

As a consequence of the very different electro-osmotic fluxes, the moisture distribution in the soil is completely different. Thus, after the treatment tests, a postmortem analysis was conducted on the two plants to map parameters with significance in understanding of the main processes that occur during the treatment. One of the parameters that was monitored (and for which a 3-D map was obtained) was the soil moisture. The results are plotted for both tests in Fig. 7.

The six cathodes-one anode strategy ( $1 \mathrm{a} 6 \mathrm{c}$ ) favors the accumulation of water in the collection tanks that were connected to cathodic wells. This fact indicates that 1a6c strategy promotes the movement of water by electroosmosis into the soil, and consequently, the soil moisture was increased. Related to this comment, 1c6a strategy provides the lower water transport (view Fig. 6). In addition, this distribution is not uniform, but instead clearly shows zones with a higher moisture value despite the symmetry of the electrode arrangements, which again suggest that heterogeneities in the soil play a very important role.

Initially, this higher evaporation should be explained in terms of a higher temperature. However, as can be observed in Fig. 8, in contrast to the expected result, no significant differences were observed between the temperatures obtained in both plants; although in the 1c6a strategy, the temperature was slightly higher, with average temperatures that are only $0.9{ }^{\circ} \mathrm{C}$ higher in the case of the 1c6a strategy (24.2 vs. $25.1^{\circ} \mathrm{C}$ ). This low increase in temperature can be explained in terms of the higher resulting intensity that was applied for this configuration. In addition, room temperature conditions in both tests (external temperature) were quite similar during the experiments. Hence, temperature is not expected to play a very relevant role and cannot explain
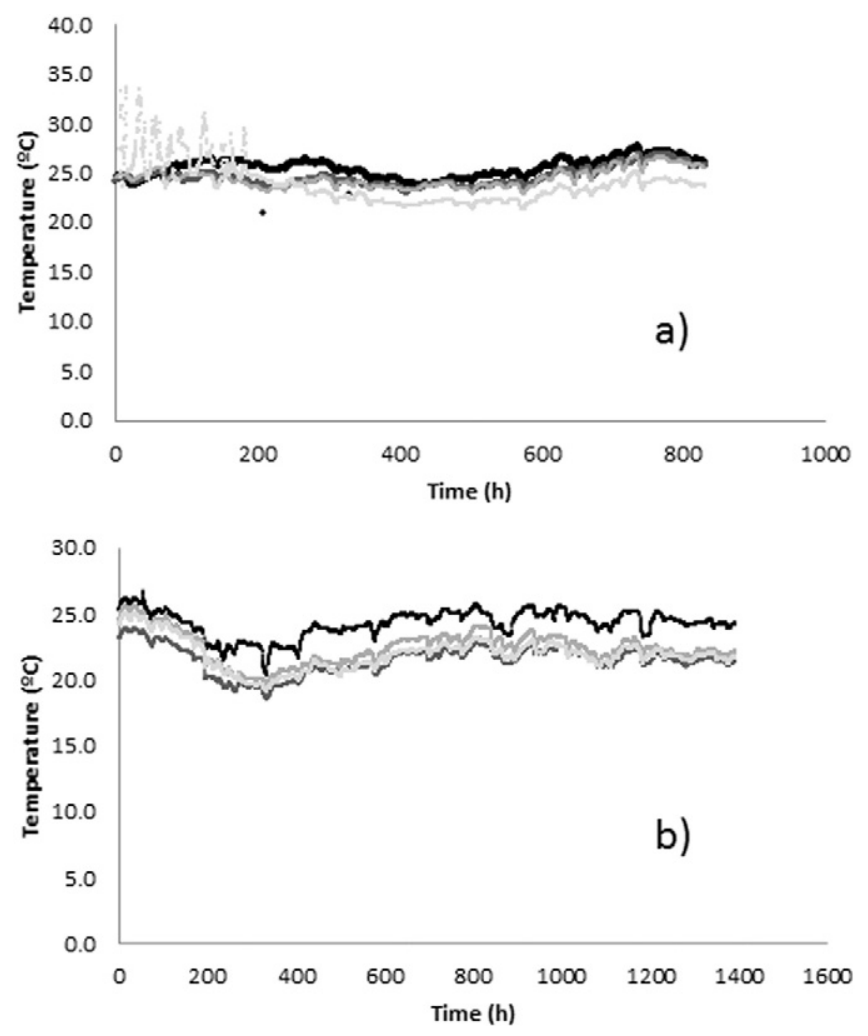

Fig. 8. Changes in the temperature in different selected positions of the soil during the two

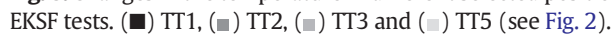

the differences in the moisture of the two soils, i.e., the configuration of
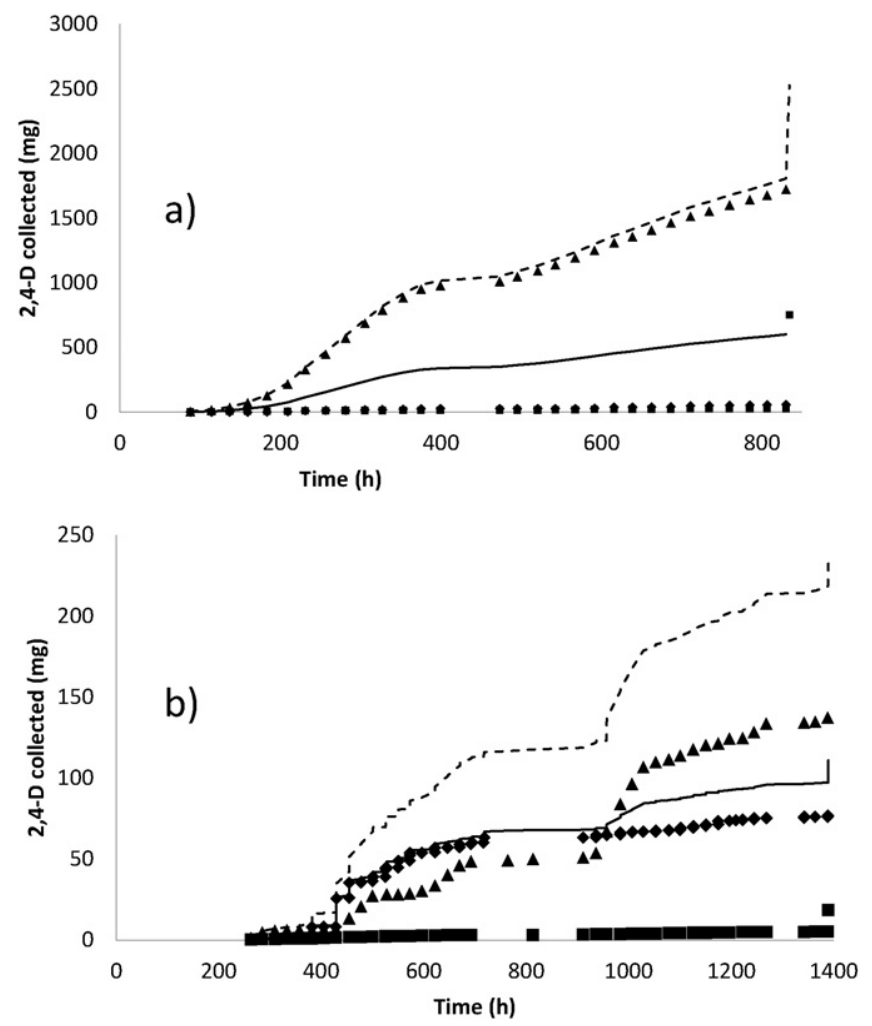

Fig. 9. 2,4-D removed with the different fluxes produced by the electric field applied in the soil: a) 1c6a arrangement and b) 1a6c arrangement. Cathodic wells $(\boldsymbol{\bullet})$, anodic wells $(\boldsymbol{\Delta})$, and gravity flux ( $\mathbf{\square})$. Continuous line: average value. Discontinuous line: total $\mathrm{mg}$ of 2,4-D collected. 

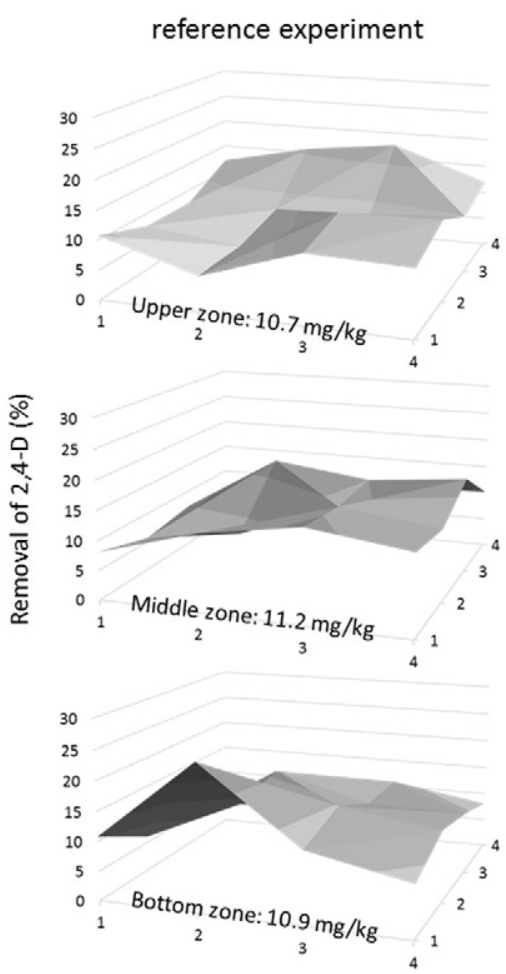

6 cathode -1 anode
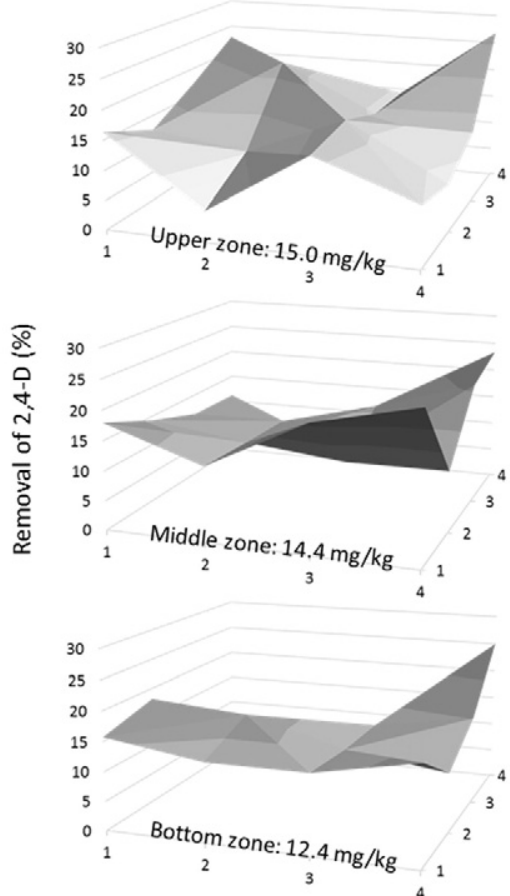

6 anodes -1 cathode
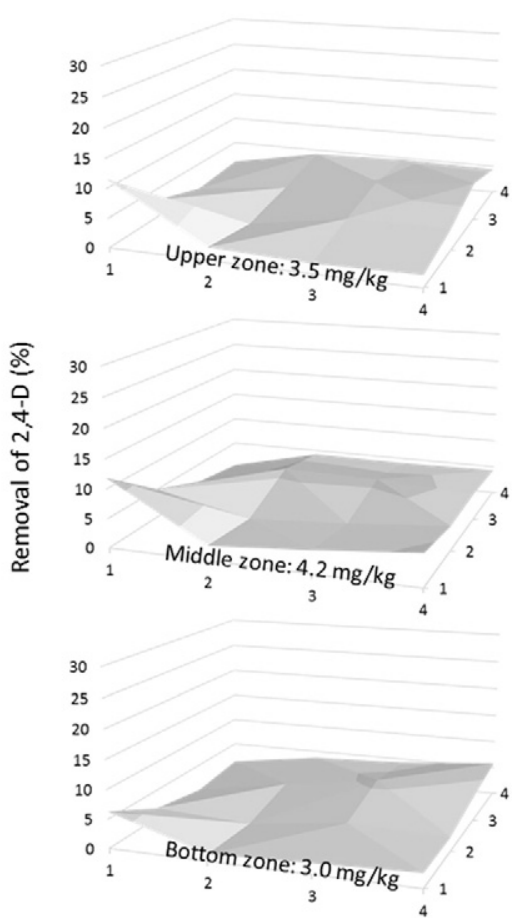

Fig. 10. 3-D maps of 2,4-D after the tests were conducted. Depth of zone $=7 \mathrm{~cm}$. The $\mathrm{X}$-axis and the $\mathrm{Z}$ axis indicate the position of the sample section.

electrodes is the only factor that can explain this higher content of water. To characterize the evaporation of water in solutions of 2,4-D, various lab-scale tests were conducted, in which the evaporation rate of water of a $500 \mathrm{mg} \mathrm{dm}^{-3} 2,4$-D solution was found to be almost constant when operating under isothermal conditions. The values obtained in that study were $0.0066 \mathrm{~cm} / \mathrm{h}$ at $22.6{ }^{\circ} \mathrm{C}$ and $0.0136 \mathrm{~cm} / \mathrm{h}$ at $28.2{ }^{\circ} \mathrm{C}$, and both values were within the range that was expected according to the mass balances that were made to the pilot plants.

\subsection{Pesticide transport}

The most important parameter in this study was the concentration of 2,4-D. Fig. 9 shows the amount of 2,4-D that was removed from the anode and cathode wells. This figure also shows the amount of 2,4-D that was drawn by the hydraulic flow that was collected at the bottom of the mockup. In comparing the values for each soil test, it can be observed that the amount of 2,4-D drained by gravity is negligible and that amount collected in the anode/s is much more significant than that collected in the cathode/s. The main mechanism explaining the transport of 2,4-D to the cathode/s is the drainage of the herbicide with electro-osmotic flux, whereas the transport to the anode is explained in terms of the electromigration caused by the negative charge of the herbicide anion (Munro et al., 1992). The results demonstrated

Table 2

Main results obtained in the remediation of the 2,4-D-polluted soils using different strategies.

\begin{tabular}{lllll}
\hline Tests/parameters & Reference & Reference & 1a6c & 1c6a \\
\hline Time & 26 & 70 & 58 & \multicolumn{1}{l}{35} \\
Average temperature & 20.3 & 20.3 & 24.20 & 25.10 \\
Average intensity (A) & - & - & 0.16 & 0.20 \\
2,4-D remaining in the soil after the & 50.27 & 45.94 & 67.68 & 15.01 \\
$\quad$ treatment (\%) & & & & \\
2,4-D removed from anode wells (\%) & - & - & 4.39 & 50.67 \\
2,4-D removed from cathode wells (\%) & - & - & 2.45 & 1.65 \\
2,4-D collected with hydraulic fluxes (\%) & - & - & 0.81 & 22.31 \\
2,4-D transferred to atmosphere (\%) & 49.73 & 54.06 & 24.66 & 10.35 \\
\hline
\end{tabular}

that the transport of pesticide in this application is favored by electromigration process, being much more important than the dragging by electroosmotic flux. In comparing the results obtained in the two tests, the six-anodes (1c6a) strategy clearly outperforms the sixcathodes (1a6c) strategy by one fold. Obviously, this strategy promotes the effect of electromigration on soil remediation with a higher number of anodes and a higher volume of electrolyte wells available to collect the herbicide. Hence, despite having a comparable geometry and number of elements, the 1c6a arrangement is much more efficient. In addition, this arrangement manages water more efficiently, and the level of moisture is not as high as in the 1a6c strategy.

To further study the influence of the electrode arrangement on the removal of the herbicide, in the post-mortem analysis conducted on the two plants after the EKSF tests, the 2,4-D distribution was monitored in different portions of the soil. Consequently, a 3-D map with the concentration of 2,4-D in the soil was obtained for each strategy. The results were compared with those obtained in a reference experiment, in which only the diffusion of the pollutant was monitored and no treatment technology was applied. Fig. 10 shows the values obtained in each horizontal layer (surface, middle and bottom layers) of the plants after the two EKSF tests and after a reference test, in which no treatment was applied.

As previously described in the experimental section, a discharge of 2,4-D was simulated, and the treatment was prepared and began after several days of this discharge. This discharge was produced in the central position of the plant on the surface of the soil; hence, due to the high concentration at this point, a substantial volatilization is expected. Note that the raw solution spilled was a solution of $500 \mathrm{mg} \mathrm{dm}^{-3}$ of 2,4D. In separate laboratory-scale experiments, the volatilization rates strongly depended on the temperature, with calculated values of $0.0002 \mathrm{mg} / \mathrm{cm}^{2} / \mathrm{h}$ at $22.6^{\circ} \mathrm{C}$ and $0.0032 \mathrm{mg} / \mathrm{cm}^{2} / \mathrm{h}$ at $28.2^{\circ} \mathrm{C}$. If a uniform distribution of the amount of 2,4-D was obtained, it led to a concentration of $20 \mathrm{mg}$ of $2,4-\mathrm{D} / \mathrm{kg}$.

The herbicide dispersion reference experiment shows that the concentration of 2,4-D in the soil after 26 days was much lower than that expected according to the simulated spill. The only mechanism that can explain this decrease in the concentration is the volatilization of 
the herbicide; this mechanism should be more important during the simulation of accidental discharge because of the higher concentration of the raw solution spilled. The 3-D map of the herbicide dispersion reference experiment also shows that the concentration of 2,4-D is homogenously distributed, both in height and in each horizontal layer, indicating that the diffusivity in soil of 2,4-D is high. In comparing these results with those of the test conducted with 6 cathodes (1a6c), the concentration of 2,4-D in the soil is found to be surprisingly much higher in this last treatment, even considering that a treatment is applied that attains the transport of the herbicide by different mechanisms. Consequently, this arrangement can be considered to favor the accumulation of water and 2,4-D in the soil, thereby preventing its evaporation by promoting a high horizontal flux of flushing fluid. Likewise, it was observed that the amount of 2,4-D that was collected in the electrolyte wells was low. In contrast, in comparing the results obtained in the reference experiment with those obtained by applying the 1c6a strategy, a very different result was obtained. A 3-D map of the 2,4-D remaining in the soil after the treatment agrees with the higher concentration of 2,4-D that was collected in the wells, particularly in the anode wells, which was associated with improved electromigration. An additional point that can help explain the differences in the volatilization of the herbicides is the capillary barrier that was placed on the treatment soil. In the case of the two electroremediation tests, the width of this barrier was twice that in the reference dispersion test.

In comparing the removal of 2,4-D in the two zones that were differentiated by the electrode arrangement (inner and outer to the circle of electrodes), it can be observed that, in contrast to the expected outcome, there is no significant difference between the zones inside and outside the electrode wells. The concentration inside is only $3.2 \%$ lower in the $1 \mathrm{a} 6 \mathrm{c}$ strategy and $18.5 \%$ in the 1c6a strategy (this latter case with a much higher removal). This fact indicates that this technology acts on the external and electrokinetic zones, thereby contributing to the effective removal of the pollutant from the soil.

Table 2 shows a summary of the main parameters of this treatment. In comparing the strategies in terms of the total removal of 2,4-D from soil, note that the 1c6a strategy is the most efficient because of the very high amount of herbicide that was transported to the anode wells. There were no important differences in the amount of 2,4-D that was transported to the cathode wells, and the volatilization of 2,4-D appears to be strongly influenced by the initial spill of the pesticide herbicide and by the water fluxes in the soil.

\section{Conclusions}

The herbicide 2,4-D can be effectively removed from spiked soils using EKSF with the configuration of electrodes consisting of circular rows of electrodes surrounding an opposite counter electrode. This arrangement is a more efficient configuration, consisting of 1 cathode surrounded by 6 anodes, than the arrangement of 1 anode surrounded by 6 cathodes because this former strategy promotes the removal of the herbicide by electromigration ( $50.7 \%$ of the herbicide). The amounts of herbicide that are dragged to cathode wells are low (below 3\%), and herbicide volatilization and water evaporation significantly influence the results (over $25 \%$ of the herbicide). However, the high fluxes and the capillary barrier appear to minimize their effect. Electro-osmotic fluxes appear to prevent the volatilization of 2,4-D from soil. The 1c6a strategy attains a transfer of $70 \%$ of the herbicide polluted to flushing fluids in only 35 days in a soil targeted to be polluted with $20 \mathrm{mg} \mathrm{kg}^{-1}$ of $2,4-\mathrm{D}$.

\section{Acknowledgments}

The authors acknowledge funding support from the EU and the Spanish Government through the MINECO Project CTM2013-45612-R,
INNOCAMPUS and CYTEMA E2TP Programs of the University of Castilla La Mancha.

\section{References}

Almeira, J., Peng, C., Wang, Z., 2009. Effect of different electrode configurations on the migration of copper ions during the electrokinetic remediation process. Asia Pac. J. Chem. Eng. 4, 581-585.

Alshawabkeh, A.N., Gale, R.J., Ozsu-Acar, E., Bricka, R.M., 1999. Optimization of 2-D electrode configuration for electrokinetic remediation. Journal of Soil Contamination 8 , 617-635.

Bian, X., Chen, J., Ji, R., 2013. Degradation of 2,4-dichlorophenoxyacetic acid (2,4-D) by novel photocatalytic material of tourmaline-coated $\mathrm{TiO} 2$ nanoparticles: kinetic study and model. Materials 6, 1530-1542.

Cho, J.-M., Kim, D.-H., Yang, J.-S., Baek, K., 2012. Electrode configuration for electrokinetic restoration of greenhouse saline soil. Sep. Sci. Technol. 47, 1677-1681.

de Velosa, A.C., Pupo Nogueira, R.F., 2013. 2,4-Dichlorophenoxyacetic acid (2,4-D) degradation promoted by nanoparticulate zerovalent iron (nZVI) in aerobic suspensions. J. Environ. Manag. 121, 72-79.

Fang, G., Si, Y., Tian, C., Zhang, G., Zhou, D., 2012. Degradation of 2,4-D in soils by Fe304 nanoparticles combined with stimulating indigenous microbes. Environ. Sci. Pollut. Res. 19, 784-793.

Fontmorin, J.-M., Fourcade, F., Geneste, F., Floner, D., Huguet, S., Amrane, A., 2013. Combined process for 2,4-dichlorophenoxyacetic acid treatment-coupling of an electrochemical system with a biological treatment. Biochem. Eng. J. 70, 17-22.

Garcia, O., Isarain-Chavez, E., Garcia-Segura, S., Brillas, E., Peralta-Hernandez, J.M., 2013 Degradation of 2,4-dichlorophenoxyacetic acid by electro-oxidation and electroFenton/BDD processes using a pre-pilot plant. Electrocatalysis 4, 224-234.

Garcia, O., Isarain-Chavez, E., El-Ghenymy, A., Brillas, E., Peralta-Hernandez, J.M., 2014 Degradation of 2,4-D herbicide in a recirculation flow plant with a Pt/air-diffusion and a BDD/BDD cell by electrochemical oxidation and electro-Fenton process. J. Electroanal. Chem. 728, 1-9.

Girardi, C., Nowak, K.M., Carranza-Diaz, O., Lewkow, B., Miltner, A., Gehre, M., Schäffer, A Kästner, M., 2013. Microbial degradation of the pharmaceutical ibuprofen and the herbicide 2,4-D in water and soil - use and limits of data obtained from aqueous systems for predicting their fate in soil. Sci. Total Environ. 444, 32-42.

Jackman, S.A., Maini, G., Sharman, A.K., Sunderland, G., Knowles, C.J., 2001. Electrokinetic movement and biodegradation of 2,4-dichlorephenoxyacetic acid in silt soil. Biotechnol. Bioeng. 74, 40-48.

Jeon, E.-K., Jung, J.-M., Kim, W.-S., Ko, S.-H., Baek, K., 2015. In situ electrokinetic remediation of As-, Cu-, and Pb-contaminated paddy soil using hexagonal electrode configuration: a full scale study. Environ. Sci. Pollut. Res. 22, 711-720.

Kim, D.-H., Jo, S.-U., Choi, J.-H., Yang, J.-S., Baek, K., 2012a. Hexagonal two dimensional electrokinetic systems for restoration of saline agricultural lands: a pilot study. Chem. Eng. J. 198, 110-121.

Kim, W.-S., Park, G.-Y., Kim, D.-H., Jung, H.-B., Ko, S.-H., Baek, K., 2012b. In situ field scale electrokinetic remediation of multi-metals contaminated paddy soil: influence of electrode configuration. Electrochim. Acta 86, 89-95.

Kim, W.-S., Jeon, E.-K., Jung, J.-M., Jung, H.-B., Ko, S.-H., Seo, C.-I., Baek, K., 2014. Field application of electrokinetic remediation for multi-metal contaminated paddy soil using two-dimensional electrode configuration. Environ. Sci. Pollut. Res. 21, 4482-4491.

Lopez-Vizcaino, R., Saez, C., Mena, E., Villasenor, J., Canizares, P., Rodrigo, M.A., 2011. Electro-osmotic fluxes in multi-well electro-remediation processes. J. Environ. Sci. Health A Tox. Hazard. Subst. Environ. Eng. 46, 1549-1557.

Lopez-Vizcaino, R., Alonso, J., Canizares, P., Leon, M., Navarro, V., Rodrigo, M., Saez, C., 2014a. Electroremediation of a natural soil polluted with phenanthrene in a pilot plant. J. Hazard. Mater. 265, 142-150.

Lopez-Vizcaino, R., Alonso, J., Canizares, P., Leon, M., Navarro, V., Rodrigo, M., Saez, C., 2014b. Removal of phenanthrene from synthetic kaolin soils by electrokinetic soi flushing. Sep. Purif. Technol. 132, 33-40.

Maya-Trevino, M.L., Villanueva-Rodriguez, M., Guzman-Mar, J.L., Hinojosa-Reyes, L. Hernandez-Ramirez, A., 2015. Comparison of the solar photocatalytic activity of $\mathrm{ZnO}-\mathrm{Fe} 2 \mathrm{O} 3$ and $\mathrm{ZnO}-\mathrm{Fe}-0$ on 2,4-D degradation in a CPC reactor. Photochem. Photobiol. Sci. 14, 543-549.

Mena, E., Rubio, P., Canizares, P., Villasenor, J., Rodrigo, M.A., 2012. Electrokinetic transport of diesel-degrading microorganisms through soils of different textures using electric fields. J. Environ. Sci. Health A Tox. Hazard. Subst. Environ. Eng. 47, 274-279.

Munro, I.C., Carlo, G.L., Orr, J.C., Sund, K.G., Wilson, R.M., Kennepohl, E., Lynch, B.S., Jablinske, M., Lee, N.L., 1992. A comprehensive, integrated review and evaluation of the scientific evidence relating to the safety of the herbicide 2,4-D. J. Am. Coll. Toxicol. $11,559$.

Niedree, B., Vereecken, H., Burauel, P., 2013. Radiation-induced impacts on the degradation of 2,4-D and the microbial population in soil microcosms. J. Environ. Radioact. $115,168-174$.

Ordaz-Guillen, Y., Juvencio Galindez-Mayer, C., Ruiz-Ordaz, N., Juarez-Ramirez, C., Santoyo-Tepole, F., Ramos-Monroy, O., 2014. Evaluating the degradation of the herbicides picloram and 2,4-D in a compartmentalized reactive biobarrier with internal liquid recirculation. Environ. Sci. Pollut. Res. 21, 8765-8773.

Page, M.M., Page, C.L., 2002. A review of electroremediation of contaminated soils. J. Environ. Eng. 81

Pazos, M., Rosales, E., Alcantara, T., Gomez, J., Sanroman, M.A., 2010. Decontamination of soils containing PAHs by electroremediation: a review. J. Hazard. Mater. 177, 1-11.

Peng, C., Almeira, J.O., Gu, Q., 2013. Effect of electrode configuration on pH distribution and heavy metal ions migration during soil electrokinetic remediation. Environmental Earth Sciences 69, 257-265. 
Ribeiro, A.B., Rodriguez-Maroto, J.M., Mateus, E.P., Gomes, H., 2005. Removal of organic contaminants from soils by an electrokinetic process: the case of atrazine. Experimental and modeling. Chemosphere 59, 1229-1239.

Ribeiro, A.B., Mateus, E.P., Rodriguez-Maroto, J.-M., 2011. Removal of organic contaminants from soils by an electrokinetic process: the case of molinate and bentazone. Experimental and modeling. Sep. Purif. Technol. 79, 193-203.

Rodrigo, M.A., Oturan, N., Oturan, M.A., 2014. Electrochemically assisted remediation of pesticides in soils and water: a review. Chem. Rev. 114, 8720-8745.

Saichek, R.E., Reddy, K.R., 2005. Electrokinetically enhanced remediation of hydrophobic organic compounds in soils: a review. Crit. Rev. Environ. Sci. Technol. 35, 115-192.

Schenone, A.V., Conte, L.O., Botta, M.A., Alfano, O.M., 2015. Modeling and optimization of photo-Fenton degradation of 2,4-D using ferrioxalate complex and response surface methodology (RSM). J. Environ. Manag. 155, 177-183.
Sheng, G.Y., Johnston, C.T., Teppen, B.J., Boyd, S.A., 2001. Potential contributions of smectite clays and organic matter to pesticide retention in soils. J. Agric. Food Chem. 49, 2899-2907.

Turer, D., Genc, A., 2005. Assessing effect of electrode configuration on the efficiency of electrokinetic remediation by sequential extraction analysis. J. Hazard. Mater. 119, 167-174.

Virkutyte, J., Sillanpaa, M., Latostenmaa, P., 2002. Electrokinetic soil remediation - critical overview. Sci. Total Environ. 289, 97-121.

Zhou, H.-y., Zeng, S.-S., Liang, S., Han, J., 2014. Degradation of 2, 4-D by combined catalytic dechlorination and biological oxidation. Huan jing ke xue = Huanjing kexue / [bian ji, Zhongguo ke xue yuan huan jing ke xue wei yuan hui "Huan jing ke xue" bian ji wei yuan hui.] 35, 3430-3435. 